\title{
Prepartum feeding behavior is an early indicator of subclinical ketosis
}

\author{
C. Goldhawk, ${ }^{*}$ N. Chapinal, ${ }^{*} †$ D. M. Veira,† D. M. Weary, ${ }^{*}$ and M. A. G. von Keyserlingk ${ }^{* 1}$ \\ ${ }^{*}$ Animal Welfare Program, Faculty of Land and Food Systems, University of British Columbia, 2357 Main Mall, Vancouver, British Columbia, \\ V6T 1Z4, Canada \\ †Agriculture and Agri-Food Canada, PO Box 1000, Agassiz, British Columbia, V0M 1A0, Canada
}

\section{ABSTRACT}

Cows diagnosed with subclinical ketosis (SCK) after calving are at increased risk of developing other diseases and compromised reproductive performance. The objective of this study was to determine whether changes in feeding and social behaviors during the transition period were associated with SCK during the week after calving. Feeding behaviors of 101 Holstein dairy cows were monitored from $3 \mathrm{wk}$ before to $3 \mathrm{wk}$ after calving. Ten otherwise healthy animals were identified as having SCK by serum $\beta$-hydroxybutyrate levels $\geq 1,000$ $\mu \mathrm{mol} / \mathrm{L}$ taken during wk +1 . These animals were matched by parity with 10 healthy animals. During the week before calving and the $2 \mathrm{wk}$ after calving, animals with SCK had lower dry matter intake, had fewer visits to the feeder, and spent less time at the feeder than healthy animals. For every 10-min decrease in average daily time spent at the feeder during the week before calving, the risk of SCK increased by 1.9 times. During the same week, a 1-kg decrease in average daily dry matter intake increased the risk of SCK by 2.2 times. The largest increase in risk of SCK was associated with a 1-kg increase in the change in average daily intake from wk -2 to -1 . During the week before calving, animals with SCK initiated fewer displacements at the feed bunk compared with animals that remained healthy after calving. The results of this study provide evidence that time spent feeding, dry matter intake, and social behavior play an important role in transition cow health. These results indicate that special consideration should be given to management and social factors that can negatively affect dry matter intake and feed bunk attendance during the transition period.

Key words: dairy cattle, subclinical ketosis, feeding behavior, dry matter intake

Received March 25, 2009.

Accepted June 16, 2009.

${ }^{1}$ Corresponding author: marina.vonkeyserlingk@ubc.ca

\section{INTRODUCTION}

During the transition period, defined as the $3 \mathrm{wk}$ before and 3 wk after calving (Grummer, 1995), there is an increase in energy demands caused by fetal growth and lactogenesis. Dairy cows often experience a decline in intake during the days before calving, which, in combination with the increase in energy demands, results in a negative energy balance during early lactation (Grummer, 1995; Drackley, 1999; Sovani et al., 2000). In an attempt to meet these increased energy demands, cows can mobilize energy stores, such as fat, in their body (Bauman and Currie, 1980), thereby increasing the production of ketone bodies in the blood. Although elevated plasma ketone levels are normal around calving, abnormally elevated levels can result in clinical or subclinical ketosis (SCK).

Approximately $30 \%$ of dairy cows experience SCK during the 2 wk after calving, when energy demands for milk production are high (Duffield et al., 1998; Duffield, 2000). Both clinical ketosis and SCK have been associated with increased risk of infectious disease and reduced reproductive performance (Reist et al., 2003; Walsh et al., 2007). However, most subclinical diseases go undiagnosed, making treatment difficult and prolonging any negative effects on herd health and productivity. Early identification of cows at risk of developing SCK could allow for timely intervention, potentially decreasing the negative effects of this disease.

Current tests for SCK are based on measuring ketone levels, mainly BHBA, in the blood, milk, and urine. Blood BHBA concentrations are currently the gold standard, but these tests are costly compared with cow-side tests (Duffield, 2000) and require time for laboratory analysis. A handheld electronic measuring device can provide a sensitive and specific cow-side test of BHBA levels in the blood of postpartum cows (Iwersen et al., 2009), but it has not been evaluated for use during the prepartum period. Therefore, these tests cannot identify at-risk animals before the onset of the disease.

Promising work in the area of early disease identification has focused on changes in feeding behavior as indicators for cows at risk of postpartum disease (Urton 
et al., 2005; Huzzey et al., 2007; Gonzalez et al., 2008). Huzzey et al. (2007), for instance, found that prepartum feeding behavior predicted the onset of mild and severe metritis postpartum. In one study that examined cows diagnosed with clinical ketosis, Gonzalez et al. (2008) found that DMI decreased $3 \mathrm{~d}$ before clinical signs of the disease were observed. Other studies have successfully induced postpartum ketonemia by restricting postpartum DMI and feeding ketogenic compounds (Drackley et al., 1992). However, no work to date has attempted to determine the predictive value of voluntary prepartum feeding behaviors on subclinical ketosis after calving.

Cows that developed metritis postpartum also engaged in fewer displacements at the feed bunk during the week before calving and avoided the feed bunk during periods when competition for feed was highest (Huzzey et al., 2007). DeVries et al. (2004) found that the effects of competition at the feed bunk were greatest for socially subordinate animals. The influence of social pressure on feeding behaviors during the prepartum period may therefore influence susceptibility to postpartum disease.

The studies by Huzzey et al. (2007) and Gonzalez et al. (2008) showed that feeding behavior could be used in the early identification of animals that later developed either infectious or metabolic diseases. Huzzey et al. (2007) also showed that social behavior at the feed bunk could differ between healthy and ill animals before the onset of illness. Thus, the objectives of this study were to investigate if feeding behavior and social behavior during the transition period would differ between animals that developed SCK after calving and those that remained healthy.

\section{MATERIALS AND METHODS}

\section{Animals, Housing, and Diet}

Between August 2005 and March 2006, a total of 32 primiparous and 69 multiparous (parity $=3.2 \pm 1.3$; mean \pm SD) Holstein dairy cows were monitored. These are the same cows as described in Huzzey et al. (2007), but the present study reports additional data that were not available at the time of that report. All animals were cared for according to the guidelines established by the Canadian Council on Animal Care (1993). Cows were housed in pre- and postpartum group pens, each maintained at 20 cows. The experimental pens provided 20 free stalls, 12 electronic feeding stations, and 2 electronic water stations (Insentec, Marknesse, the Netherlands; see Chapinal et al., 2007, for a description and validation of this system). Cows entered the prepartum pen $25 \pm 2 \mathrm{~d}$ before the expected calving date and were moved to the maternity pen when they showed signs of imminent calving (i.e., udder enlargement, milk letdown, relaxation of tail ligament). The maternity pen consisted of a sand-bedded pack with 6 Insentec feeders and 1 Insentec water trough. Cows were moved to the postpartum pen within $24 \mathrm{~h}$ of calving and were monitored for an additional $21 \mathrm{~d}$. After calving, cows were milked twice daily at approximately 0700 and $1700 \mathrm{~h}$.

Pre- and postpartum groups were fed a TMR at approximately 0800 and $1600 \mathrm{~h}$. A detailed description of the nutrient analysis for each diet can be found in Huzzey et al. (2007).

\section{Behavioral Data Collection}

Individual feeding behavior was monitored with the Insentec electronic feeding system. Body weights were measured by averaging BW taken on 3 consecutive days at entry into the trial, calving, and $21 \mathrm{~d}$ postpartum. The same trained observers determined BCS at $\mathrm{d}-20$ $\pm 2, \mathrm{~d}-10 \pm 2$, and every $3 \mathrm{~d}$ after calving (on a scale of 1 to 5, according to the method of Wildman et al., 1982). Cows were identified as having a retained placenta if the placenta was observed hanging from the vulva beyond $24 \mathrm{~h}$ after calving. Every $3 \mathrm{~d}$ after calving until +21 d, cows were subjected to a clinical examination to identify mastitis, metritis, milk fever, and abomasal displacements and to measure rectal temperature by using a digital thermometer (GLA M525/550, GLA Agricultural Electronics, San Luis Obispo, CA). Udder hardness, heat, and clots or discolored milk were used to identify clinical mastitis. Milk samples were taken at $\mathrm{d}+3,+4,+6,+7,+14,+15,+20$, and +21 and were analyzed for fat, protein, and lactose.

During health exams, blood samples were collected from the coccygeal vein using Vacutainer tubes (Vacutainer Venous Blood Collection Tubes, BD Biosciences, Franklin Lakes, NJ). Blood samples were allowed to clot for $3 \mathrm{~h}$ at room temperature and then centrifuged at 789.6 relative centrifugal force for $10 \mathrm{~min}$. Serum was removed and stored at $-20^{\circ} \mathrm{C}$ until being sent to the University of Guelph Animal Health Laboratory (Ontario, Canada) for analysis of BHBA with a Hitachi 911 autoanalyzer (Roche Diagnostics, Hoffman-La Roche Ltd., Montreal, Quebec, Canada).

\section{Case Definition and Cow Participation in Study}

Because of the association between disease and feeding behavior during the transition period (e.g., see Huzzey et al., 2007), animals diagnosed with any clinical diseases, including ketosis, retained placenta, or metritis, were excluded from the study. Measurements of serum 
BHBA levels during the week after calving were used to classify animals as having SCK. A threshold of serum BHBA $>1,000 \mu \mathrm{mol} / \mathrm{L}$ in any sample taken on $\mathrm{d} 0,+3$, or +6 was used to classify animals as having SCK based on the criteria used by Walsh et al. (2007). Animals with $\mathrm{BHBA} \geq 1,400 \mu \mathrm{mol} / \mathrm{L}$ in wk +2 or later were not included because this has been shown to be indicative of prolonged negative energy balance and is often associated with clinical ketosis (Walsh et al., 2007). Cows with $\mathrm{BHBA}<1,000 \mu \mathrm{mol} / \mathrm{L}$ were considered healthy.

Application of these criteria resulted in 9 multiparous cows and 1 primiparous cow diagnosed with SCK during the week after calving. One animal was identified on d $0(\mathrm{BHBA}=1,096 \mu \mathrm{mol} / \mathrm{L}), 8$ were identified on $\mathrm{d}+3$ (BHBA ranging from 1,083 to $2,179 \mu \mathrm{mol} / \mathrm{L}$ ), and 1 was identified on $\mathrm{d}+6(\mathrm{BHBA}=1,071 \mu \mathrm{mol} / \mathrm{L})$. Three of the 6 cows identified on $\mathrm{d}+3$ also had elevated BHBA levels on $d+6$. These 10 animals with SCK were balanced for parity and calving difficulty with 10 healthy animals. The 10 healthy animals had an average BHBA of $567 \pm 50 \mu \mathrm{mol} / \mathrm{L}$ (mean $\pm \mathrm{SE}$ ) during wk +1 , with a maximum BHBA of $871 \mu \mathrm{mol} / \mathrm{L}$. No animals in either group had BHBA levels $>1,000$ $\mu \mathrm{mol} / \mathrm{L}$ before calving.

The SCK and healthy groups had an average parity of $1.8 \pm 0.4$ (mean $\pm \mathrm{SE}$; range 1 to 4 ) and $1.3 \pm 0.3$ (range 1 to 3 ), respectively. The average BCS before calving for animals with SCK and for healthy animals was $3.5 \pm 0.06$ and $3.4 \pm 0.05$ (mean $\pm \mathrm{SE}$ ), respectively. The average BCS after calving was $3.3 \pm 0.05$ and $3.3 \pm 0.05$ (mean $\pm \mathrm{SE}$ ) for animals with SCK and for healthy animals, respectively.

\section{Social Behavior Data Collection}

Two video cameras (closed-circuit television camera, model WV-BP330, Panasonic, Osaka, Japan) were mounted over the feed bunk in both the pre- and postpartum pens and the cameras continuously recorded behavior throughout the experiment. Red lights (100 W) were hung adjacent to the cameras to facilitate recording during low lighting (e.g., nighttime). Hair dye was used to mark the back and side of animals with alphanumeric symbols for easy identification of individuals. Displacements during the $3 \mathrm{~h}$ after the morning and afternoon feeding (peak feeding activity; DeVries et al., 2004) were recorded from 3 d selected randomly during the week before calving. An animal was recorded as the actor in a displacement when its head came in contact with an animal that was feeding, followed by the animal that was feeding removing its head from the feed bin. An animal was recorded as a reactor when it was physically displaced from the feed bin. The actor was recorded as successful if it accessed the bin from which the reactor was removed. One animal was removed from the analysis of social behavior for the SCK group because of missing videotape. The total number of times that an animal was the actor during an interaction was averaged over the $3 \mathrm{~d}$ of video recording, providing a single value for each animal.

\section{Statistical Analysis}

Complete data on feeding behavior were available from $14 \mathrm{~d}$ before calving until $21 \mathrm{~d}$ after calving. Normality of the data was analyzed using the UNIVARIATE procedure (SAS Institute, 2003), and 3\% of the values were identified as extreme outliers (3 interquartile ranges beyond the first or third quartile of the data set) and were removed. Feeding data were summarized into 5 periods based on week relative to calving: wk -2 (d -14 to -8$)$, wk -1 ( $d-7$ to -1$)$, wk $+1(\mathrm{~d}+1$ to +7$)$, $\mathrm{wk}+2(\mathrm{~d}+8$ to +14$)$, and $\mathrm{wk}+3(\mathrm{~d}+15$ to +21$)$. The day of calving ( $\mathrm{d} 0$ ) was not included because of variation in the time and duration of calving.

Differences in feeding behavior (DMI, feeding time, feeding rate) and water intake of healthy and SCK cows were analyzed using the MIXED procedure (Version 9.1; SAS Institute, 2003) by period. Period was treated as a repeated measure with cow as the subject and with a compound symmetry covariance matrix. Parity was not included in any model because groups were balanced for parity. To detect differences in DMI between the SCK and healthy groups, cow was considered the experimental unit and the model included the fixed effects of health (SCK or healthy), weekly period, and the interaction between health and weekly period. Dry matter intake was also considered as a percentage of BW; however, the results were not different from unadjusted values. Thus, only the unadjusted values are presented.

Preliminary analyses revealed that SCK cows were slightly heavier than healthy animals (average BW at $\mathrm{wk}-2$ : healthy $=716.8 \mathrm{~kg} \pm 24.03, \mathrm{SCK}=769.3 \mathrm{~kg} \pm$ 24.03) at the beginning of the trial, although there was no significant effect of $\mathrm{BW}$ at wk -2 on health $(P=$ $0.14)$ or on the change in intake from wk -2 to $-1(P$ $=0.3)$. Thus, BW is not discussed further.

To determine the predictive value of DMI and other variables (days on a close-up diet, gestation length, change in DMI from wk -2 to -1 , pre- and postcalving $\mathrm{BCS}$ ) on the risk of SCK, multivariable logistic regression was done using the LOGISTIC procedure (SAS Institute, 2003). Each variable was initially tested individually, and variables with $P<0.1$ were retained in the final logistic model. Variables retained in the final model included DMI, feeding time, number of visits to the feeder during wk -1 , and the change in intake from 

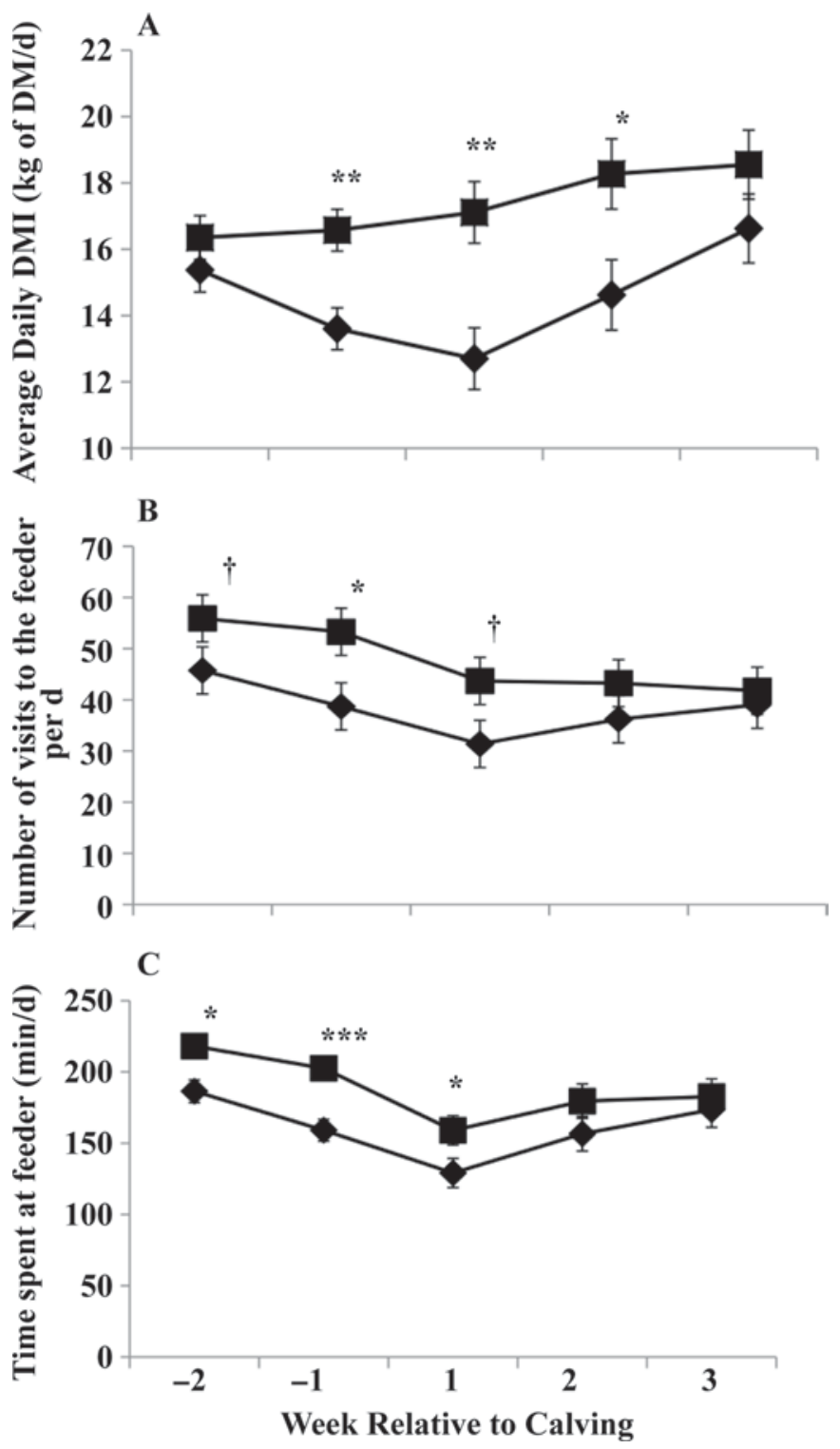

Figure 1. Least squares mean $( \pm \mathrm{SE})$ for $\mathrm{A}) \mathrm{DMI}, \mathrm{B})$ number of visits to the feeder, and C) time spent at the feeder for Holstein dairy cows that were healthy $(\boldsymbol{\square}, \mathrm{n}=10)$ or that had subclinical ketosis $(\bullet$ $\mathrm{n}=10)$ during the transition period. $\dagger P<0.1 ;{ }^{*} P<0.05 ;{ }^{*} P<0.01$; *** $P<0.001$.

wk -2 to -1 . Similar to the report of Huzzey et al. (2007), increased intake during wk -1 was associated with increased time spent at the feeder $\left(\mathrm{R}^{2}=0.55, P=\right.$ 0.01 ) and increased time spent at the feeder was associated with an increased number of visits to the feeder $\left(\mathrm{R}^{2}=0.53, P=0.02\right)$. In addition, higher DMI during wk -1 was associated with a greater change in intake from wk -2 to $-1\left(\mathrm{R}^{2}=0.54, P=0.01\right)$. Thus, the odds ratios reported are from separate models to avoid including highly related variables in the same model.

Average daily milk production was analyzed during 3 periods (d 4 to 21 , d 22 to 60, and d 60 to 120 after calving). Differences in milk production between the healthy and SCK groups were analyzed using a mixed model in which period was treated as a repeated measure, cow was treated as the subject, and the model had a compound symmetry covariance matrix. Analysis of fixed effects was carried out in the following order: health, period, and health $\times$ period interaction.

Differences in the average number of times an animal was an actor per day between health groups were tested using a $t$-test. Primiparous animals show different social behavior than multiparous animals during the transition period (Proudfoot et al., 2009); thus, primiparous animals were not included in the analysis of social behavior.

\section{RESULTS}

\section{DMI and Feeding Behavior}

During wk $-1,+1$, and +2 , the DMI of cows with SCK was 18, 26, and $20 \%$ lower that the DMI of cows that remained healthy after calving $(P<0.01$; Figure 1A). These animals also visited the feeder 18, 27, 28, and $16 \%$ fewer times during wk $-2,-1,+1$, and +2 (Figure 1B) and spent less time at the feeder the same weeks (Figure 1C). There were no differences in the rate at which SCK or healthy animals consumed DM during the 5 wk of the trial (healthy $=0.1 \pm 0.01 \mathrm{~kg}$ of DM/ min, $\mathrm{SCK}=0.1 \pm 0.01 \mathrm{~kg}$ of $\mathrm{DM} / \mathrm{min}, P=0.91)$. For both SCK and healthy animals, feeding rate increased by approximately $23 \%$ from wk -1 to +1 . There was a trend for the water intake of SCK cows to be lower during wk -2 and -1 (wk -2 : healthy $=45.2 \pm 4.2$ $\mathrm{kg}, \mathrm{SCK}=36.7 \pm 4.2 \mathrm{~kg}, P=0.07$; wk -1 : healthy $=$ $44.6 \pm 4.2 \mathrm{~kg}, \mathrm{SCK}=34.7 \pm 4.2 \mathrm{~kg}, P=0.03)$. There were no differences in the time spent at the water bin (healthy $=12.3 \pm 1.43 \mathrm{~min} / \mathrm{d}$, SCK $=12.3 \pm 1.43$ $\min / \mathrm{d}, P=0.99)$ or the number of visits to the water bin during any week in the trial (healthy $=10.58 \pm 0.9$ visits $/ \mathrm{d}, \mathrm{SCK}=9.42 \pm 0.9$ visits $/ \mathrm{d}, P=0.35)$.

\section{Logistic Regression}

During the week before calving, reductions in average daily DMI, visits to the feeder, and feeding time, as well as larger changes in average daily DMI from wk -2 to -1 , increased the risk of developing SCK. The risk of a cow being diagnosed with SCK increased 2.2 times for every 1-kg decrease in average daily DMI during wk $-1\left[P_{\text {Wald }}=0.02,95 \%\right.$ confidence interval $\left(\mathbf{C I}_{\mathbf{9 5}}\right)=1.1$, 4.3]. This model explained $49 \%$ of the variation in the risk of SCK $\left(P_{\text {Likelihood Ratio }}<0.01\right)$. The model for time spent at the feeder accounted for $57 \%$ of the variation in risk $\left(P_{\text {Likelihood Ratio }}<0.001\right)$, with the risk of SCK 
increasing by 1.9 times for every 10-min decrease in average daily feeding time during wk $-1\left(P_{\text {Wald }}=0.01\right.$, $\left.\mathrm{CI}_{95}=1.15,3.13\right)$. When the average number of visits to the feeder per day during wk -1 was substituted for time spent at the feeder, the model accounted for $36 \%$ of the variation in risk $\left(P_{\text {Likelihood Ratio }}=0.01\right)$. Reducing the average number of visits during wk -1 by 10 increased the risk of SCK by 3.5 times $\left(P_{\text {Wald }}=0.05\right.$, $\left.\mathrm{CI}_{95}=0.96,12.34\right)$. A $1-\mathrm{kg}$ decrease in average daily DMI from wk -2 to -1 increased the risk of developing SCK by 4.0 times $\left(P_{\text {Wald }}=0.03, \mathrm{CI}_{95}=1.14,14.29\right)$, and the model accounted for $51 \%$ of the variation in risk $\left(P_{\text {Likelihood Ratio }}=0.002\right)$.

\section{Milk Production}

Average daily milk production during the first 21 $\mathrm{d}$ after calving did not differ between health groups (healthy $=42.12 \pm 2.4 \mathrm{~kg}$, SCK $=42.70 \pm 2.4 \mathrm{~kg}$, $P=0.86)$. There was also no difference in total milk production during any of the 3 periods tested.

\section{Social Behavior at the Feed Bunk}

The average number of times in wk -1 that a multiparous animal was the actor was higher for healthy animals than for SCK animals (healthy $=14.4 \pm 1.83$ displacements as actor/d, SCK $=10.2 \pm 0.62$ displacements as actor/d, $P=0.05$ ).

\section{DISCUSSION}

The reported incidence of SCK in lactating dairy cows is dependent on the sensitivity of the methods used to detect ketones and the threshold values used to diagnose the disease. Using the same threshold as in our study, Walsh et al. (2007) reported a 36\% incidence when 796 Holstein dairy cows were tested on 25 farms in Ontario. Other studies have used a higher threshold than that used in the current study (1,200 to 1,400 $\mu \mathrm{mol} / \mathrm{L}$; Duffield, 2000), but more recent work suggests that reproductive performance is impaired when BHBA levels exceed 1,000 $\mu \mathrm{mol} / \mathrm{L}$ during $\mathrm{wk}+1$ (Walsh et al., 2007).

Reduced DMI is a well-recognized sign of clinical ketosis in dairy cattle (Duffield, 2000). Gonzalez et al. (2008) found that several days before the diagnosis of clinical ketosis, the fresh matter intake of sick animals was $10 \mathrm{~kg} / \mathrm{d}$ lower than normal. In the current study, DMI was $3 \mathrm{~kg} / \mathrm{d}$ lower in SCK animals than in their healthy counterparts during the week before diagnosis of SCK in wk +1 . Considering that our diet was approximately $50 \% \mathrm{DM}$, the reduction in intake during the week before calving (i.e., the week before diagnosis of SCK) was slightly smaller than that found by Gonzalez et al. (2008); this difference is not surprising, given that the cows in the present study were diagnosed with SCK and not clinical ketosis. To our knowledge, this is the first study reporting declines in intake and feeding behavior in association with the event of calving for cows that were diagnosed with SCK during the week after calving.

Similar to the report by Huzzey et al. (2007), cows in our study that were diagnosed as ill postpartum spent less time at the feed bunk, visited the feeder less often, and consumed less DMI in the week before calving. Huzzey et al. (2007) reported that a 1-kg decrease in DMI during wk -1 increased the risk of metritis by 2.87 times, which is similar to the increase of 2.2 times in the risk of SCK found in our study. Huzzey et al. (2007) and Urton et al. (2005) reported that a 10-min decrease in average daily feeding time during the week before calving was associated with an increase of 1.7 and 1.6 times in the risk of metritis, respectively, which is similar to the 1.9-fold increased risk of SCK in our study. We also found that every 1-kg decline in the change in average daily DMI from wk -2 to -1 was associated with an increase of 4.0 times in the risk of SCK. The results of the current study, combined with the findings of Huzzey et al. (2007) and Urton et al. (2005), provide evidence that feeding behavior and DMI during the week before calving are important risk factors for postpartum disease.

For a variable to be useful in early identification of animals at risk of developing a disease, it must be characteristic of the disease and precede diagnosis (Gonzalez et al., 2008). Given these criteria, the association between DMI, feeding behaviors, and increased risk of uncomplicated SCK in wk +1 found in our study indicates that these variables are likely suitable for prepartum identification of animals at risk of developing postpartum SCK. Although the current technology required to monitor feeding behavior and individual intakes accurately on commercial dairies is expensive, these systems provide objective measures that are readily accessible and useful in early identification of animals at risk of developing postpartum SCK. More research is needed to establish values of feeding behaviors (e.g., DMI during wk -1 and the change in average daily DMI from wk -2 to -1 ) that are cutoff values predictive of an increased risk of SCK. Additional research should also focus on ways to incorporate these variables into practical on-farm disease-monitoring systems.

Cows that developed SCK had a lower water intake during the 2 wk prepartum. This result was expected, given the relationship between DMI and water con- 
sumption (Murphy, 1992). Lukas et al. (2008) reported that water intake could be used as an alternative to monitoring DMI for disease identification, but Huzzey et al. (2007) found that reduced water intake during wk -1 was far less useful than reduced DMI in predicting metritis.

Subclinical ketosis is believed to be associated with the increasing energy requirements during the early postpartum period. The lack of difference in milk yield between healthy and SCK animals, despite SCK animals having lower DMI, indicates that the requirements for milk production were met through energy sources other than feed.

Similar to the results of Huzzey et al. (2007), animals in our study that were diagnosed as ill postpartum engaged in fewer displacements at the feed bunk during peak feeding periods in the week before calving. Because competitive social environments are known to alter feeding behavior (e.g., Huzzey et al. 2006), reduced displacements at the feed bunk indicated that animals that became ill $1 \mathrm{wk}$ later were less motivated to compete for feed before calving. Proudfoot et al. (2009) showed that when fed in a competitive environment, multiparous cows tended to have lower DMI during the prepartum period than cows that were fed in a noncompetitive environment, likely increasing the risk of subclinical disease in competitively fed cows. The stocking density in our experiment was approximately 1.7 cows per feed bin; this is slightly lower than the 2:1 stocking density used by Proudfoot et al. (2009), but likely resulted in competition at the feed bunk. Whether competition influenced the motivation to feed or vice versa is unclear; however, the results of this study and others (e.g., Huzzey et al. 2007; Proudfoot et al., 2009) provide evidence in support of the hypothesis that prepartum social interactions can influence postpartum health. More research is necessary, particularly with primiparous cows, to determine if there is a direct relationship between social status and postpartum disease.

\section{CONCLUSIONS}

Animals that developed SCK during the week after calving showed differences in feeding behavior and DMI as early as 1 wk before calving. Animals with SCK also initiated fewer displacements at the feed bunk during the week before calving. The results of our study highlight the importance of implementing management practices that reduce competition and increase feed bunk access, particularly in the prepartum period, because these are likely to be key factors in the prevention of diseases common to the transition period.

\section{ACKNOWLEDGMENTS}

We thank the staff of The University of British Columbia Dairy Education and Research Centre and the university's Animal Welfare Program. This work would not have been possible without the contributions of Katy Proudfoot and Julie Huzzey (Animal Welfare Program, University of British Columbia, Vancouver) during the data collection phase. Christy Goldhawk was funded through the Natural Sciences and Engineering Research Council (NSERC) Postgraduate Scholarship Masters (PGSM) program (Ottawa, Ontario, Canada) and the Canadian Dairy Commission (Ottawa, Ontario, Canada) Graduate Scholarship program. This project was funded by the NSERC of Canada Discovery Program and the NSERC Collaborative Research Program, together with the Dairy Farmers of Canada (Ottawa, Ontario, Canada), and many other donors listed on the Animal Welfare Web site at http://www.landfood.ubc. ca/animalwelfare.

\section{REFERENCES}

Bauman, D. E., and W. B. Currie. 1980. Partitioning of nutrients during pregnancy and lactation: A review of mechanisms involving homeostasis and homeorhesis. J. Dairy Sci. 63:1514-1529.

Canadian Council on Animal Care. 1993. Guide to the Care and Use of Experimental Animals. Vol 1. E. D. Olfert, M. Cross, and A. A. McWilliam, ed. CCAC, Ottawa, Ontario, Canada.

Chapinal, N., D. M. Viera, D. M. Weary, and M. A. G. von Keyserlingk. 2007. Technical note: Validation of a system for monitoring individual feeding and drinking behaviour and intake in grouphoused cattle. J. Dairy Sci. 90:5732-5736.

DeVries, T. J., M. A. G. von Keyserlingk, and D. M. Weary. 2004. Effect of feeding space on the intercow-distance, aggression, and feeding behavior of free-stall housed lactating dairy cows. J. Dairy Sci. 87:1432-1438.

Drackley, J. K., M. J. Richard, D. C. Beitz, and J. W. Young. 1992. Metabolic changes in dairy cows with ketonemia in response to feed restriction and dietary 1,3-butanediol. J. Dairy Sci. 75:16221634.

Drackley, J. K. 1999. Biology of dairy cows during the transition period: The final frontier? J. Dairy Sci. 82:2259-2273.

Duffield, T. 2000. Subclinical ketosis in lactating dairy cattle. Vet. Clin. North Am. Food Anim. Pract. 16:231-253.

Duffield, T. F., D. Sandals, K. E. Leslie, K. Lissemore, B. W. McBride, J. H. Lumsden, P. Dick, and R. Bagg. 1998. Efficacy of monensin for prevention of subclinical ketosis in lactating dairy cows. J. Dairy Sci. 81:2866-2873.

Gonzalez, L. A., B. J. Tolkamp, M. P. Coffey, A. Ferret, and I. Kyriazakis. 2008. Changes in feeding behavior as possible indicators for the automatic monitoring of health disorders in dairy cows. J. Dairy Sci. 91:1017-1028.

Grummer, R. R. 1995. Impact of changes in organic nutrient metabolism on feed the transition cow. J. Anim. Sci. 73:2820-2833.

Huzzey, J. M., T. J. DeVries, P. Valois, and M. A. G. von Keyserlingk. 2006. Stocking density and feed barrier design affect the feeding and social behavior of dairy cattle. J. Dairy Sci. 89:126-133.

Huzzey, J. M., D. M. Veira, D. M. Weary, and M. A. G. von Keyserlingk. 2007. Prepartum behavior and dry matter intake identify dairy cows at risk for metritis. J. Dairy Sci. 90:3220-3233.

Iwersen, M., U. Falkenberg, R. Voigtsberger, D. Forderung, and W. Heuwieser. 2009. Evaluation of an electronic cowside test to detect subclinical ketosis in dairy cows. J. Dairy Sci. 92:2618-2624. 
Lukas, J. M., J. K. Reneau, and J. G. Linn. 2008. Water intake and dry matter intake changes as a feeding management tool and indicator of health and estrus status in dairy cows. J. Dairy Sci. 91:3385-3394.

Murphy, M. R. 1992. Symposium: Nutritional factors affecting animal water and waste quality: Water metabolism of dairy cows. J. Dairy Sci. 75:326-333.

Proudfoot, K. L., D. M. Veira, D. M. Weary, and M. A. G. von Keyserlingk. 2009. Competition at the feed bunk changes the feeding, standing, and social behavior of transition dairy cows. J. Dairy Sci. 92:3116-3123.

Reist, M., D. K. Erdin, D. von Euw, K. M. Tschümperlin, H. Leuenberger, H. M. Hammon, N. Künzi, and J. W. Blum. 2003. Use of threshold serum and milk ketone concentrations to identify risk for ketosis and endometritis in high yielding dairy cows. Am. J. Vet. Res. 64:188-194.

SAS Institute. 2003. SAS User's Guide. Version 9.1. SAS Institute Inc., Cary, NC.
Sovani, S., C. Heuer, W. M. VanStraalen, and J. P. T. M. Noordhuizen. 2000. Disease in high producing dairy cows following post parturient negative energy balance. Pages 33-50 in Soc. Vet. Epid. Prev. Med. Prod., Edinburgh, UK. Soc. Vet. Epidemiol. Prev. Med., UK.

Urton, G., M. A. G. von Keyserlingk, and D. M. Weary. 2005. Feeding behavior identifies dairy cows at risk for metritis. J. Dairy Sci. 88:2843-2849.

Walsh, R. B., J. S. Walton, D. F. Kelton, S. J. LeBlanc, K. E. Leslie, and T. F. Duffield. 2007. The effect of subclinical ketosis in early lactation on reproductive performance of postpartum dairy cows. J. Dairy Sci. 90:2788-2796.

Wildman, E. E., G. M. Jones, P. E. Wagner, R. L. Boman, H. F. Troutt, and T. N. Lesch. 1982. A dairy cow body condition scoring system and its relationship to selected production characteristics. J. Dairy Sci. 65:495-501. 